\title{
BMJ Open Association of anthropometric indices of obesity with hypertension among public employees in northern Ethiopia: findings from a cross-sectional survey
}

KM Saif-Ur-Rahman (D) ${ }^{1,2}$ Chifa Chiang, ${ }^{1}$ Lemlem Weldegerima Gebremariam, ${ }^{3}$ Esayas Haregot Hilawe, ${ }^{1}$ Yoshihisa Hirakawa, ${ }^{1}$ Atsuko Aoyama, ${ }^{1,4}$ Hiroshi Yatsuya (1) ${ }^{1,5}$

To cite: Saif-Ur-Rahman KM, Chiang C, Weldegerima Gebremariam L, et al. Association of anthropometric indices of obesity with hypertension among public employees in northern Ethiopia: findings from a crosssectional survey. BMJ Open 2021;11:e050969. doi:10.1136/ bmjopen-2021-050969

- Prepublication history and additional supplemental material for this paper are available online. To view these files, please visit the journal online (http://dx.doi.org/10.1136/ bmjopen-2021-050969).

Received 05 March 2021 Accepted 05 September 2021

Check for updates

(C) Author(s) (or their employer(s)) 2021. Re-use permitted under CC BY-NC. No commercial re-use. See rights and permissions. Published by BMJ.

For numbered affiliations see end of article.

Correspondence to

Dr Hiroshi Yatsuya;

h828@med.nagoya-u.ac.jp

\section{ABSTRACT}

Objectives The burden of hypertension is increasing in low-income countries, including Ethiopia. Obesity is widely known to be associated with hypertension, but different anthropometric indices of obesity might differ in association with hypertension, which is largely unknown in northern Ethiopia.

Design Data from our previous cross-sectional epidemiological survey were statistically analysed. Setting Public employees in the regional capital city in northern Ethiopia

Participants The data of 1380 participants (823 men and 557 non-pregnant women) aged 25 and 64 years were analysed.

Outcome measures The presence of hypertension was the outcome measure and multivariable-adjusted logistic regression analyses were used to investigate the association of body mass index (BMI), waist circumference, and waist-hip ratio in men and women separately. The area under the curve (AUC) for three anthropometric indices for discriminating hypertension was also obtained. Separate analyses were conducted for waist circumference and waist-hip ratio analyses further adjusted for BMI.

Results BMI was linearly associated with hypertension in men (OR for 1 SD increase in BMI 1.45, $p=0.001$ ) and women (OR for $1 \mathrm{SD}$ increase in $\mathrm{BMl} 1.41, p=0.01$ ). The association of waist circumference was independent of $\mathrm{BMI}$ both in men (OR for $1 \mathrm{SD}$ increase in waist circumference: $1.74, p=0.002$ ) and women (OR for 1 SD increase in waist circumference: $1.57, p=0.029$ ). The association of waist-hip ratio with hypertension adjusted for BMI was significant in men (OR for 1 SD increase in the waist-hip ratio: $1.46, p<0.001$ ), but was weak and nonsignificant in women. The AUC for BMI was 0.64 in men and 0.67 in women, while AUC for waist circumference was 0.69 both in men and women.

Conclusions Waist circumference was associated with hypertension independent of $\mathrm{BMI}$ among public employees in northern Ethiopia.

\section{INTRODUCTION}

Hypertension is a major global public health concern, accounting for 10.8 million deaths
Strengths and limitations of this study

- This is the first study to investigate the difference of anthropometric indices of obesity in association with hypertension in northern Ethiopia separately for sex.

- Potential confounding of socioeconomic and behavioural variables was statistically controlled, and further adjustment for body mass index was applied to explore the association of abdominal indices of obesity with hypertension.

- Anthropometric indices were measured by welltrained data collectors following the standard protocol of WHO; however, there might be interobserver errors in measuring waist and hip circumference.

Due to the nature of a cross-sectional study, causal relationships could not be identified.

in 2019 globally. ${ }^{1-5}$ The WHO reported that the age-standardised prevalence of hypertension in low-income and middle-income countries was higher than that in high-income countries. ${ }^{67}$

Ethiopia is a low-income country in subSaharan Africa with over 102 million populations and experienced over $10 \%$ of annual economic growth in the past decade. ${ }^{8}$ While communicable diseases are still prevalent, non-communicable diseases (NCD) accounted for $39 \%$ of all deaths in Ethiopia in $2018 .^{7}$ A nationwide NCD risk factor survey in 2015 reported that the prevalence of hypertension was $15.7 \%$ in men and $16.5 \%$ in women, ${ }^{9} 10$ and a recent survey conducted in southern Ethiopia reported $19.3 \%$ in men and $14.2 \%$ in women as well. ${ }^{11}$ Prevention and control of hypertension are urgently required in countries such as Ethiopia, of which healthcare systems are yet insufficient to manage cardiac diseases and stroke, or serious consequences of hypertension. ${ }^{12}$ 
Since the data and information on the prevalence of NCD risk factors were still scarce in northern Ethiopia, we conducted a cross-sectional epidemiological study on NCD risk factors ${ }^{13}$ and a qualitative study on perception and attitude towards NCD risk factors ${ }^{14}$ among public employees in a regional capital city in northern Ethiopia. Our epidemiological study showed that the agestandardised prevalence of hypertension was $22.4 \%$ in men and $15.3 \%$ in women.

Obesity is a well-known determinant factor of hypertension. ${ }^{15-17}$ Anthropometric indices of obesity include body mass index (BMI), waist circumference, and waist-hip ratio, and the latter two indices are supposed to indicate the degree of abdominal obesity. ${ }^{18}$ As obesity is one of the most important determinants of hypertension, ${ }^{15-17}$ public health efforts to prevent and control excess weight need to be strengthened ${ }^{19}$ together with other measures such as reducing salt intake. ${ }^{20}$ Appropriate anthropometric indices need to be identified to monitor the progress of such public health interventions, as different anthropometric indices might have a different association with hypertension. Previous studies in England, Iran, Sweden and Brazil showed that the association of BMI, waist circumference and waist-hip ratio with hypertension, but the findings were not consistent among the studies. ${ }^{21-24}$ A study in southern Ethiopia examined the predictability of anthropometric indices for hypertension, without adjusting for age and other behavioural factors. ${ }^{15}$ However, the difference in association with hypertension among anthropometric indices has not yet been investigated in northern Ethiopia.

Thus, we examined the associations of BMI, an index of general obesity, and the anthropometric indices of abdominal obesity, which were waist circumference and waist-hip ratio with hypertension. This study aimed to explore the difference in association with hypertension among anthropometric indices of obesity, including BMI, waist circumference and waist-hip ratio, among public employees in northern Ethiopia.

\section{METHODS}

\section{Data source}

We used the dataset obtained from the cross-sectional epidemiological survey of NCD risk factors conducted between October 2015 and February 2016, targeting public employees between 25 and 64 years of age in a regional capital city in northern Ethiopia. The details of the survey were described elsewhere ${ }^{13}$ In total, 1527 participants (869 men and 658women) partook in the study. Excluding pregnant women $(\mathrm{n}=22)$, individuals younger than 25 years old $(n=98)$, and individuals whose age or sex was unknown $(n=27)$, the data of 1380 participants (823 men and 557women) were statistically analysed.

\section{Variables}

Hypertension was defined as systolic blood pressure $(\mathrm{SBP}) \geq 140 \mathrm{~mm} \mathrm{Hg}$ and diastolic blood pressure
(DBP) $\geq 90 \mathrm{~mm} \mathrm{Hg} . \quad \mathrm{SBP} / \mathrm{DBP}<120 / 80 \mathrm{~mm} \mathrm{Hg}$ was considered as normal. ${ }^{25-27}$

BMI, calculated as weight in kilograms divided by height in metres squared, was categorised into five groups: $<21.0,21.0-22.9,23.0-24.9,25.0-27.4$ and $\geq 27.5 \mathrm{~kg} / \mathrm{m}^{2}$. We collapsed the $<18.5$ and $\geq 30 \mathrm{~kg} / \mathrm{m}^{2}$ category, underweight and obesity according to the WHO definition, and merged them with the adjacent categories. Waist circumference was categorised into five groups: $\leq 80.9,81.0-84.9$, $85.0-90.9,91.0-94.0$ and $>94 \mathrm{~cm}$. Waist-hip ratio was categorised into four groups: $<0.80,0.81-0.84,0.85-0.89$ and $\geq 0.90$.

Age, marital status, income, smoking, khat chewing, alcohol drinking, fruit and vegetable intake were considered as covariates. All the variables were categorised as dichotomised groups except age which was continuous: income, $\geq 3001$ and $<3000$ Ethiopian birrs per month on average; marital status, currently married and single/separated; smoking/khat chewing, ever smoked/chewed and never smoked/chewed; alcohol drinking, $1-7$ and $<1$ day per week; fruit and vegetable intake, $\geq 3$ and $<3$ servings per day.

\section{Statistical analysis}

Age-adjusted proportion (\%) of sociodemographic and behavioural variables, estimated using the general linear model, was demonstrated according to BMI, waist circumference and waist-hip ratio categories according to sex. The binominal logistic regression model was applied to explore the relationship of different anthropometric indices with hypertension. The logistic regression models for three anthropometric variables were initially adjusted for age (continuous) only. Subsequently, further adjustment was done for the following covariates for each anthropometric variable: income, marital status, smoking, khat chewing, alcohol drinking and fruit and vegetable intake. For the analyses of waist circumference and waisthip ratio analyses, continuous BMI was also adjusted on top of the aforementioned covariates. The linear association of the three anthropometric indices with hypertension was evaluated using the continuous variables. In each model, the OR for the increment of 1 SD BMI, 1 SD waist circumference, 1 SD waist-hip ratio was presented with the corresponding 95\% CI. In addition, the area under the receiver operating characteristic curve was calculated using univariable logistic regression. It is equivalent to c-index, an overall measure of discrimination indicating the ability of a model (the variable) to distinguish individuals who have hypertension from those who do not. ${ }^{28}$ The area under the curve (AUC) was presented along with the $95 \%$ CI to aid our comparison among three anthropometric variables. All the analysis was conducted using SPSS software V.23.0.

\section{Patient and public involvement}

Patients or the public were not involved in the design, or conduct, or reporting, or dissemination plans of our research. 
Table 1 Age-adjusted proportion of sociodemographic and behavioural variables according to body mass index categories and sex, \%

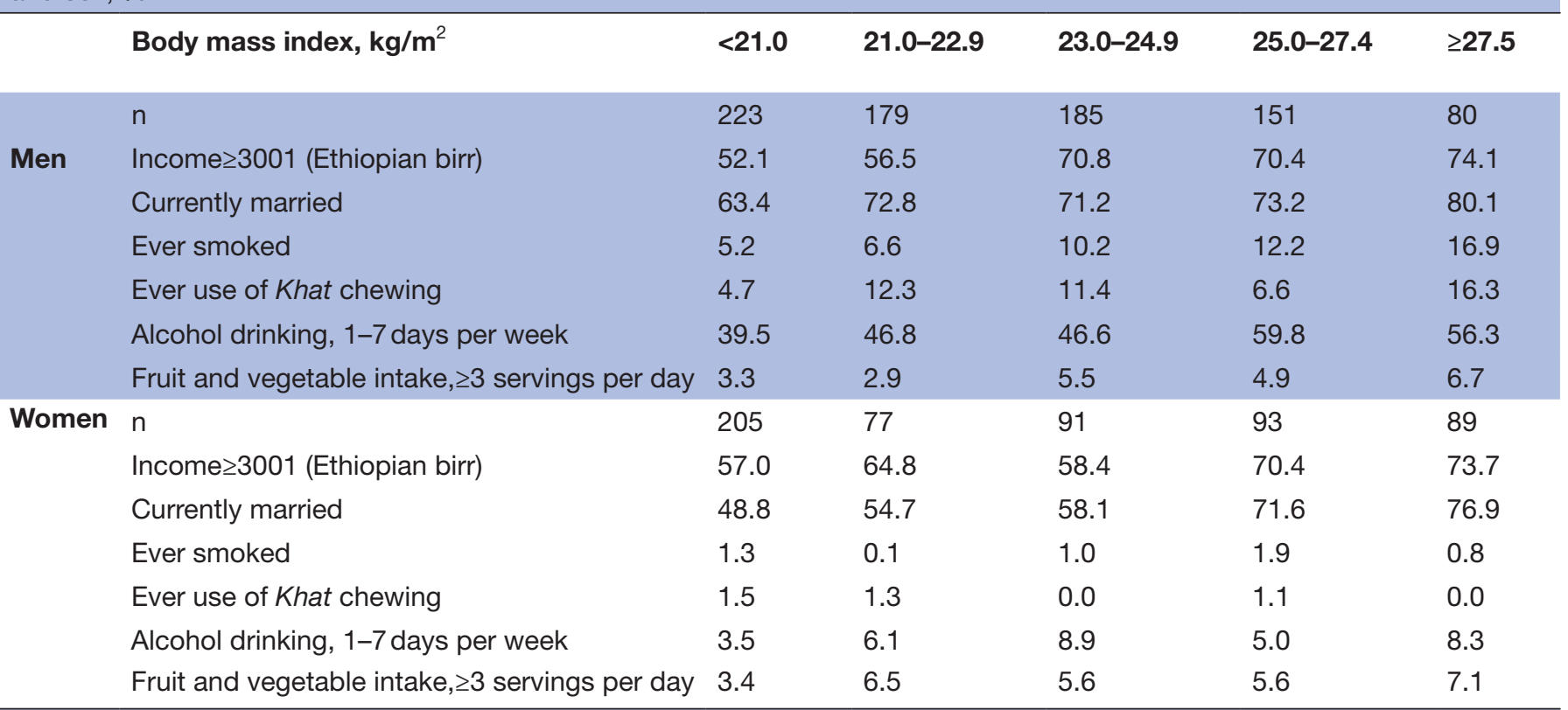

\section{RESULTS}

The mean age was 39.5 years (mean age \pm SD: $39.5 \pm 9.4$ ). The mean SBP was $119.6 \mathrm{~mm} \mathrm{Hg}$ (mean SBP \pm SD: 119.6 \pm 16.7 ), and the mean DBP was $80 \mathrm{~mm} \mathrm{Hg}$ (mean $\mathrm{DBP} \pm \mathrm{SD}: 79.9 \pm 9.9)$. The overall prevalence of hypertension was $19.6 \%$ ( $22.4 \%$ in men and $15.3 \%$ in women).

The age-adjusted proportion of having average monthly income $\geq 3001$ Ethiopian birrs was $52.1 \%$ in the lowest BMI group, and $74.1 \%$ in the highest BMI group in men, whereas, $57.0 \%$ and $73.7 \%$ in the lowest and highest BMI groups respectively in women (table 1). Similarly, the age-adjusted proportion of married, ever smoking/khat chewing, alcohol drinking, $\geq 3$ servings of fruit and vegetable intake increased from the lowest to the highest BMI groups both in men and women. Similar findings were observed in the age-adjusted proportions of these covariates according to waist circumference and waist-hip ratio (online supplemental table 1 and 2).

BMI, waist circumference and waist-hip ratio were significantly associated with hypertension both in men (table 2) and women (table 3). In men, BMI was linearly associated with hypertension (OR for 1 SD BMI: 1.45, $\mathrm{p}=0.001)$ significantly, and the OR of having hypertension was 2.92 (95\% CI 1.46 to 5.83 ) in the highest BMI category compared with the lowest BMI category (multivariable adjusted model). Similarly, waist circumference was linearly associated with hypertension (OR for $1 \mathrm{SD}$ increase in waist circumference: $1.67, \mathrm{p}<0.001)$, and the association was independent of BMI (OR for 1 SD waist circumference: $1.74, \mathrm{p}=0.002)$. The waist-hip ratio was also linearly associated with hypertension (OR for $1 \mathrm{SD}$ increase in the waist-hip ratio: $1.56, \mathrm{p}<0.001)$. The association was also significant after further adjustment for BMI (OR for $1 \mathrm{SD}$ increase in the waist-hip ratio: 1.46 , $\mathrm{p}<0.001)$.
In women, BMI was also linearly associated with hypertension (OR for 1 SD BMI: 1.41, $\mathrm{p}=0.011$ ). The OR of having hypertension in the highest BMI category was 3.68 (95\% CI 1.62 to 8.39 ) compared with the lowest category in multivariable adjusted model. Waist circumference was linearly associated with hypertension (OR for $1 \mathrm{SD}$ increase in waist circumference was $1.70, \mathrm{p}=0.001)$. This association was also independent of BMI (OR for 1 SD increase in waist circumference: $1.57, \mathrm{p}=0.029)$. The waist-hip ratio was linearly associated with hypertension only in the age-adjusted model (OR for $1 \mathrm{SD}$ increase in the waist-hip ratio: $1.31, \mathrm{p}=0.030)$. The association was obscured after adjustment for variables in multivariable adjusted model (OR for 1 SD waist-hip ratio: 1.31, $\mathrm{p}=0.056$ ), and after further adjustment for BMI (OR for 1 SD waist-hip ratio: $1.25, \mathrm{p}=0.13$ ) in multivariable adjusted and continuous BMI adjusted model.

The AUC for BMI was 0.64 in men and 0.67 in women (table 4). AUC for waist circumference was 0.69 both in men and women, and AUC for the waist-hip ratio was 0.70 in men and 0.64 in women.

\section{DISCUSSION}

This study examined the association of obesity measured by anthropometric indices with hypertension among public employees in northern Ethiopia. BMI, waist circumference and waist-hip ratio were associated with hypertension independent of socioeconomic and behavioural variables in men. Waist circumference was associated with hypertension independent of BMI both in men and women; however, the waist-hip ratio was associated with hypertension independent of BMI only in men but not women. As far as we know, this is the first study 
Table 2 OR and $95 \% \mathrm{Cl}$ of body mass index (BMI), waist circumference, and waist-hip ratio with hypertension in men

\begin{tabular}{|c|c|c|c|c|c|c|}
\hline BMI, kg/m2 & $<21.0$ & $21.0-22.9$ & 23.0-24.9 & $25.0-27.4$ & $\geq 27.5$ & OR 1 \\
\hline $\mathrm{n}$ of cases $/ \mathrm{N}$ & $25 / 223$ & $38 / 179$ & $46 / 185$ & $45 / 151$ & $29 / 80$ & \\
\hline Age-adjusted OR & 1 & $\begin{array}{l}1.67 \\
(0.94 \text { to } 2.94)\end{array}$ & $\begin{array}{l}2.15 \\
(1.24 \text { to } 3.73)\end{array}$ & $\begin{array}{l}2.49 \\
\text { (1.42 to } 4.37)\end{array}$ & $\begin{array}{l}3.20 \\
(1.69 \text { to } 6.07)\end{array}$ & $\begin{array}{l}1.32 \\
(1.10 \text { to } 1.57)\end{array}$ \\
\hline Multivariable adjusted OR & 1 & $\begin{array}{l}1.27 \\
(0.70 \text { to } 2.33)\end{array}$ & $\begin{array}{l}1.87 \\
\text { (1.04 to } 3.33)\end{array}$ & $\begin{array}{l}2.06 \\
\text { (1.12 to } 3.80)\end{array}$ & $\begin{array}{l}2.92 \\
(1.46 \text { to } 5.83)\end{array}$ & $\begin{array}{l}1.45 \\
\text { (1.17 to } 1.78)\end{array}$ \\
\hline Waist circumference, $\mathrm{cm}$ & $<80$ & $81.0-84.9$ & $85.0-90.9$ & $91.0-94.0$ & $>94$ & OR 2 \\
\hline$n$ of cases $/ \mathrm{N}$ & $17 / 175$ & $17 / 118$ & $27 / 159$ & $24 / 111$ & $100 / 254$ & \\
\hline Age adjusted OR & 1 & $\begin{array}{l}1.35 \\
\text { (0.65 to } 2.80)\end{array}$ & $\begin{array}{l}1.55 \\
\text { (0.80 to } 3.01)\end{array}$ & $\begin{array}{l}1.86 \\
\text { (0.93 to } 3.72)\end{array}$ & $\begin{array}{l}3.98 \\
(2.22 \text { to } 7.11)\end{array}$ & $\begin{array}{l}1.74 \\
\text { (1.43 to } 2.12)\end{array}$ \\
\hline Multivariable adjusted OR & 1 & $\begin{array}{l}1.11 \\
(0.51 \text { to } 2.41)\end{array}$ & $\begin{array}{l}1.30 \\
(0.65 \text { to } 2.57)\end{array}$ & $\begin{array}{l}1.41 \\
\text { (0.67 to } 2.96)\end{array}$ & $\begin{array}{l}3.30 \\
(1.78 \text { to } 6.10)\end{array}$ & $\begin{array}{l}1.67 \\
\text { (1.35 to } 2.07)\end{array}$ \\
\hline $\begin{array}{l}\text { Multivariable } \\
\text { adjusted+continuous BMI } \\
\text { adjusted OR }\end{array}$ & 1 & $\begin{array}{l}0.99 \\
\text { (0.44 to } 2.22)\end{array}$ & $\begin{array}{l}1.24 \\
\text { (0.60 to } 2.53)\end{array}$ & $\begin{array}{l}1.34 \\
\text { (0.60 to } 2.99)\end{array}$ & $\begin{array}{l}2.96 \\
\text { (1.34 to } 6.54)\end{array}$ & $\begin{array}{l}1.74 \\
(1.22 \text { to } 2.47)\end{array}$ \\
\hline Waist-hip ratio & $>0.80$ & & $0.81-0.84$ & $0.85-0.89$ & $\geq 0.90$ & OR 3 \\
\hline$n$ of cases $/ \mathrm{N}$ & $5 / 58$ & & $10 / 94$ & $21 / 165$ & $141 / 414$ & \\
\hline Age-adjusted OR & 1 & & $\begin{array}{l}1.27 \\
(0.41 \text { to } 4.00)\end{array}$ & $\begin{array}{l}1.32 \\
(0.46 \text { to } 3.74)\end{array}$ & $\begin{array}{l}3.47 \\
(1.32 \text { to } 9.11)\end{array}$ & $\begin{array}{l}1.61 \\
\text { (1.33 to } 1.95)\end{array}$ \\
\hline Multivariable-adjusted OR & 1 & & $\begin{array}{l}1.11 \\
\text { (0.33 to } 3.68)\end{array}$ & $\begin{array}{l}1.42 \\
\text { (0.49 to } 4.08)\end{array}$ & $\begin{array}{l}3.16 \\
(1.18 \text { to } 8.45)\end{array}$ & $\begin{array}{l}1.56 \\
(1.28 \text { to } 1.91)\end{array}$ \\
\hline $\begin{array}{l}\text { Multivariable } \\
\text { adjusted+continuous BMI- } \\
\text { adjusted OR }\end{array}$ & 1 & & $\begin{array}{l}1.14 \\
(0.34 \text { to } 3.83)\end{array}$ & $\begin{array}{l}1.35 \\
\text { (0.46 to } 3.92)\end{array}$ & $\begin{array}{l}2.59 \\
\text { (0.95 to } 7.06)\end{array}$ & $\begin{array}{l}1.46 \\
(1.19 \text { to } 1.78)\end{array}$ \\
\hline
\end{tabular}

$\mathrm{n}$ indicates number of hypertension within the category; $\mathrm{N}$ indicates number of subjects within the category.

Multivariable adjusted: adjusted for age, income, marital status, smoking, khat chewing, alcohol drinking and fruit and vegetable intake.

Multivariable adjusted+continuous BMl adjusted: adjusted for age, income, marital status, smoking, khat chewing, alcohol drinking, fruit and vegetable intake and continuous BMI.

OR 1, OR for 1 SD body mass index with $95 \% \mathrm{Cl}$; OR 2, OR for 1 SD waist circumference with 95\% Cl; OR 3, OR for 1 SD waist hip ratio with $95 \% \mathrm{Cl}$.

to investigate the difference of anthropometric indices of obesity in association with hypertension in northern Ethiopia.

It is well established that the degree of obesity measured by various anthropometric indices was associated with hypertension. ${ }^{15-17}$ Similar to our findings, BMI and waist circumference were associated with hypertension in southern Ethiopia, ${ }^{15}$ China, ${ }^{29} \operatorname{Iran}^{22}$ and England ${ }^{21}$ without adjusting socioeconomic and behavioural covariates, and in Sweden, after adjusted for socio-economic covariates. ${ }^{24}$ Our study showed that the waist-hip ratio was significantly associated with hypertension only in men independent of BMI. In women, BMI, not waist-hip ratio was associated with hypertension in that model, which might be consistent with a previous study in Japan that reported sex differences in the association of abdominal obesity with hypertension. ${ }^{28}$ But it would be inconsistent with studies conducted in southern Ethiopia, ${ }^{15}$ Iran, ${ }^{22}$ and England, ${ }^{21}$ in which no sex difference was observed. Indeed, the AUC of waist-hip ratio was the highest among the three anthropometric indices of obesity in men, but the lowest in women in the present study. The lack of, or weaker association of waist-hip ratio with hypertension, although regardless of sex, was reported by others as well. ${ }^{29}{ }^{30}$ These findings might indicate that the waisthip ratio could be a predictor of hypertension only in men in this population. Sex difference in the association between waist-hip ratio and hypertension shown in this study might be due to the sex difference in body fat distribution, or predominant subcutaneous fat distribution in women, ${ }^{31}$ and to the lower prevalence of increased waist circumference and increased waist-hip ratio in women than men in this population, ${ }^{13}$ but further studies are certainly required.

This study found that abdominal obesity measured by waist circumference was associated with hypertension independent of BMI while BMI was not significantly associated with hypertension after adjusted for waist circumference (data not shown). We also found that the AUC of waist circumference was higher than the AUC of BMI both in men and women, although the difference was not so much. These findings indicated that waist circumference could be a better predictor of hypertension than BMI consistent with previous studies. ${ }^{32-34}$ However, some studies reported inconsistent findings: a metaanalysis of studies conducted in the Asia-Pacific region 
Table 3 OR and 95\% Cl of body mass index (BMI), waist circumference, and waist-hip ratio with hypertension in women

\begin{tabular}{|c|c|c|c|c|c|c|}
\hline BMI, kg/m2 & $<21.0$ & $21.0-22.9$ & $23.0-24.9$ & $25.0-27.4$ & $\geq 27.5$ & OR 1 \\
\hline $\mathrm{n}$ of cases/N & $25 / 223$ & $38 / 179$ & $46 / 185$ & $45 / 151$ & $29 / 80$ & \\
\hline Age-adjusted OR & 1 & $\begin{array}{l}2.06 \\
(0.90 \text { to } 4.70)\end{array}$ & $\begin{array}{l}2.06 \\
(0.95 \text { to } 4.50)\end{array}$ & $\begin{array}{l}1.46 \\
\text { (0.65 to } 3.27)\end{array}$ & $\begin{array}{l}4.25 \\
(2.08 \text { to } 8.66)\end{array}$ & $\begin{array}{l}1.47 \\
\text { (1.15 to }\end{array}$ \\
\hline
\end{tabular}

\begin{tabular}{|c|c|c|c|c|c|c|}
\hline & & & & & & 1.86) \\
\hline $\mathrm{n}$ of cases/N & $17 / 175$ & $17 / 118$ & $27 / 159$ & $24 / 111$ & $100 / 254$ & \\
\hline Age-adjusted OR & 1 & $\begin{array}{l}1.57 \\
\text { (0.62 to } 3.93)\end{array}$ & $\begin{array}{l}1.54 \\
\text { (0.65 to } 3.68)\end{array}$ & $\begin{array}{l}2.91 \\
(1.30 \text { to } 6.49)\end{array}$ & $\begin{array}{l}3.52 \\
(1.75 \text { to } 7.07)\end{array}$ & $\begin{array}{l}1.71 \\
(1.30 \text { to } \\
2.26)\end{array}$ \\
\hline Multivariable-adjusted OR & 1 & $\begin{array}{l}1.52 \\
\text { (0.56 to } 4.12)\end{array}$ & $\begin{array}{l}1.66 \\
(0.64 \text { to } 4.28)\end{array}$ & $\begin{array}{l}2.63 \\
(1.07 \text { to } 6.48)\end{array}$ & $\begin{array}{l}3.08 \\
(1.35 \text { to } 7.04)\end{array}$ & $\begin{array}{l}1.70 \\
(1.23 \text { to } \\
2.34)\end{array}$ \\
\hline $\begin{array}{l}\text { Multivariable } \\
\text { adjusted+continuous BMI } \\
\text { adjusted OR }\end{array}$ & 1 & $\begin{array}{l}1.36 \\
(0.49 \text { to } 3.73)\end{array}$ & $\begin{array}{l}1.41 \\
(0.53 \text { to } 3.76)\end{array}$ & $\begin{array}{l}2.14 \\
\text { (0.83 to } 5.53)\end{array}$ & $\begin{array}{l}2.27 \\
(0.88 \text { to } 5.88)\end{array}$ & $\begin{array}{l}1.57 \\
(1.05 \text { to } \\
2.35)\end{array}$ \\
\hline Age-adjusted OR & 1 & & $\begin{array}{l}0.94 \\
(0.38 \text { to } 2.30)\end{array}$ & $\begin{array}{l}1.36 \\
(0.61 \text { to } 3.03)\end{array}$ & $\begin{array}{l}2.28 \\
(1.09 \text { to } 4.76)\end{array}$ & $\begin{array}{l}1.31 \\
(1.03 \text { to } \\
1.67)\end{array}$ \\
\hline Multivariable-adjusted OR & 1 & & $\begin{array}{l}1.03 \\
(0.39 \text { to } 2.76)\end{array}$ & $\begin{array}{l}1.14 \\
(0.46 \text { to } 2.82)\end{array}$ & $\begin{array}{l}2.15 \\
(0.95 \text { to } 4.89)\end{array}$ & $\begin{array}{l}1.31 \\
(0.99 \text { to } \\
1.73)\end{array}$ \\
\hline $\begin{array}{l}\text { Multivariable } \\
\text { adjusted+continuous BMI } \\
\text { adjusted OR }\end{array}$ & 1 & & $\begin{array}{l}0.97 \\
(0.36 \text { to } 2.63)\end{array}$ & $\begin{array}{l}1.07 \\
(0.43 \text { to } 2.65)\end{array}$ & $\begin{array}{l}1.88 \\
(0.81 \text { to } 4.36)\end{array}$ & $\begin{array}{l}1.25 \\
(0.94 \text { to } \\
1.67)\end{array}$ \\
\hline
\end{tabular}

$\mathrm{n}$ indicates number of hypertension within the category; $\mathrm{N}$ indicates number of people within the category.

Multivariable adjusted: adjusted for age, income, marital status, smoking, khat chewing, alcohol drinking and fruit and vegetable intake.

Multivariable adjusted+continuous BMI adjusted: adjusted for age, income, marital status, smoking, khat chewing, alcohol drinking, fruit and vegetable intake and continuous BMI.

OR 1 , OR for 1 SD body mass index with 95\% Cl; OR 2, OR for 1 SD waist circumference with 95\% Cl; OR 3, OR for 1 SD waist hip ratio with $95 \% \mathrm{Cl}$.

did not suggest the existence of systematic differences among different anthropometric variables in their relation to hypertension. ${ }^{35}$ Several studies found a stronger association of BMI with hypertension than waist circumference. ${ }^{3637}$ The reasons for such discrepancies among previous studies are not clear but it might be in part due to the difference in the ethnicity, sex, or targeted age groups among these studies as the inter-individual variation in the degree of abdominal obesity might be limited in some of these studies.

Table 4 The area under the receiver operating characteristic curve for the relationship between hypertension and anthropometric indices (unadjusted)

\begin{tabular}{lllll}
\hline \multirow{2}{*}{ Men } & & Area under the curve (AUC) & SE & 95\% CI \\
& Body mass index & 0.64 & 0.02 & 0.59 to 0.68 \\
& Waist circumference & 0.69 & 0.02 & 0.65 to 0.74 \\
\multirow{2}{*}{ Women } & Waist-hip ratio & 0.70 & 0.02 & 0.66 to 0.75 \\
& Body mass index & 0.67 & 0.03 & 0.61 to 0.73 \\
& Waist circumference & 0.69 & 0.03 & 0.03 \\
\hline
\end{tabular}


Our study found that waist circumference was significantly associated with hypertension after adjustment for BMI. This indicates that changes in waist circumference should be monitored during the hypertension control interventions, such as diet management and physical exercise, rather than just monitoring body weight. Waist circumference can be measured even in a resource-poor setting in developing countries. Also, regular screening of BMI and waist circumference would be useful to predict risks of hypertension.

The strength of our study is that we, for the first time, examined the difference of anthropometric indices of obesity in association with hypertension in northern Ethiopia. We applied logistic regression models adjusted for socioeconomic and behavioural variables and further adjusted for BMI to explore the association of anthropometric indices of obesity with hypertension. The findings of the current study could be a basis for hypertension control programmes in northern Ethiopia, which we piloted previously. ${ }^{38}$ The limitation of this study is that due to the nature of a cross-sectional study, causal relationships could not be identified. Another limitation is that there might be interobserver errors in measuring waist circumference and hip circumference. However, anthropometric indices were measured by well-trained data collectors following the WHO standard protocol, so such errors were likely to be minimum.

In conclusion, the current study showed that the association of waist circumference with hypertension was independent of BMI among northern Ethiopian public employees. Abdominal obesity measured by waist circumference could be a good predictor of hypertension in this population.

\section{Author affiliations}

${ }^{1}$ Public Health and Health Systems, Nagoya University Graduate School of Medicine Faculty of Medicine, Nagoya, Aichi, Japan

${ }^{2}$ Health Systems and Population Studies Division, ICDDRB, Dhaka, Bangladesh

${ }^{3}$ Department of Public Health, Mekelle University College of Health Sciences,

Mekelle, Tigray, Ethiopia

${ }^{4}$ Nagoya University of Arts and Sciences, Nisshin, Aichi, Japan

${ }^{5}$ Department of Public Health, Fujita Health University School of Medicine Graduate School of Medicine, Toyoake, Aichi, Japan

Acknowledgements The authors wish to thank public employees in Mekelle, and staff members of the field survey, Tigray Provincial Health Bureau, Mekelle University College of Health Sciences for assistance in data collection and valuable advice.

Contributors HY, KMS-U-R, CC, LWG, EHH and AA designed the study. KMS-U-R, $\mathrm{HY}$ and $\mathrm{CC}$ statistically analysed and interpreted the data. KMS-U-R and HY drafted the manuscript, and $\mathrm{YH}$ and $\mathrm{AA}$ provided critical input on the draft. All authors reviewed and approved the final version of the manuscript.

Funding This work was supported by Grants-in-Aid for Scientific Research (KAKENHI) from the Japan Society for the Promotion of Science (B, 26293147 to $A A)$, and in part by Sciences Research Grant for Research on Global Health Issues from the Japan Agency for Medical Research and Development (16jk0110008h0102 to AA).

Disclaimer The funders had no roles in the study design, data collection, data analysis, preparation of the manuscript, and the decision to submit it for publication.

Competing interests None declared.
Patient consent for publication Consent obtained directly from patient(s)

Ethics approval Bioethics Review Committee of Nagoya University Graduate School of Medicine, Japan, and the Institutional Review Board of Mekelle University College of Health Sciences, Ethiopia.

Provenance and peer review Not commissioned; externally peer reviewed.

Data availability statement The data analysed during this study is not publicly available, but could be made available after appropriate procedures including approval from the institutional ethics review committee. Available from the corresponding author on request.

Supplemental material This content has been supplied by the author(s). It has not been vetted by BMJ Publishing Group Limited (BMJ) and may not have been peer-reviewed. Any opinions or recommendations discussed are solely those of the author(s) and are not endorsed by BMJ. BMJ disclaims all liability and responsibility arising from any reliance placed on the content. Where the content includes any translated material, BMJ does not warrant the accuracy and reliability of the translations (including but not limited to local regulations, clinical guidelines, terminology, drug names and drug dosages), and is not responsible for any error and/or omissions arising from translation and adaptation or otherwise.

Open access This is an open access article distributed in accordance with the Creative Commons Attribution Non Commercial (CC BY-NC 4.0) license, which permits others to distribute, remix, adapt, build upon this work non-commercially, and license their derivative works on different terms, provided the original work is properly cited, appropriate credit is given, any changes made indicated, and the use is non-commercial. See: http://creativecommons.org/licenses/by-nc/4.0/.

ORCID iDs

KM Saif-Ur-Rahman http://orcid.org/0000-0001-8702-7094

Hiroshi Yatsuya http://orcid.org/0000-0002-6220-9251

\section{REFERENCES}

1 Alberti KGMM, Eckel RH, Grundy SM, et al. Harmonizing the metabolic syndrome: a joint interim statement of the International diabetes Federation Task force on epidemiology and prevention; National heart, lung, and blood Institute; American heart association; world heart Federation; international atherosclerosis Society; and international association for the study of obesity. Circulation 2009;120:1640-5.

2 Habib GB, Virani SS, Jneid H. Is 2015 the primetime year for prehypertension? prehypertension: a cardiovascular risk factor or simply a risk marker? J Am Heart Assoc 2015;4:e001792.

3 Huang Y, Cai X, Liu C, et al. Prehypertension and the risk of coronary heart disease in Asian and Western populations: a meta-analysis. $J$ Am Heart Assoc 2015;4:e001519.

4 GBD 2019 Risk Factors Collaborators. Global burden of 87 risk factors in 204 countries and territories, 1990-2019: a systematic analysis for the global burden of disease study 2019. Lancet 2020;396:1223-49.

5 Roth GA, Mensah GA, Johnson CO, et al. Global burden of cardiovascular diseases and risk factors, 1990-2019: update from the GBD 2019 study. J Am Coll Cardiol 2020;76:2982-3021.

6 World Health Organization. Noncommunicable diseases country profiles, 2014. Available: https://www.who.int/nmh/publications/ncdprofiles-2014/en/ [Accessed 9 Feb 2021].

7 World Health Organization. Noncommunicable diseases country profile, 2018. Available: https://www.who.int/nmh/publications/ncdprofiles-2018/en/ [Accessed 9 Feb 2021].

8 The World Bank. World development indicators. Available: https:// data.worldbank.org/country/Ethiopia [Accessed 9 Feb 2021].

9 Ethiopian Public Health Institute, Federal Ministry of Health, World Health Organization. Ethiopia steps report on risk factors for noncommunicable diseases and prevalence of selected NCDS, 2016. Available: https://www.who.int/ncds/surveillance/steps/ethiopia/en/ [Accessed 9 Feb 2021].

10 World Health Organization. Ethiopia steps survey 2015 fact sheet, 2015. Available: https://www.who.int/ncds/surveillance/steps/ ethiopia/en/ [Accessed 9 Feb 2021].

11 Dereje N, Earsido A, Temam L, et al. Uncovering the high burden of hypertension and its predictors among adult population in Hosanna town, southern Ethiopia: a community-based cross-sectional study. BMJ Open 2020;10:e035823.

12 Eregata GT, Hailu A, Memirie ST, et al. Measuring progress towards universal health coverage: national and subnational analysis in Ethiopia. BMJ Glob Health 2019;4:e001843. 
13 Gebremariam LW, Chiang C, Yatsuya H, et al. Non-Communicable disease risk factor profile among public employees in a regional City in northern Ethiopia. Sci Rep 2018;8:9298.

14 Gebremariam LW, Aoyama A, Kahsay AB, et al. Perception and practice of 'healthy' diet in relation to noncommunicable diseases among the urban and rural people in northern Ethiopia: a community-based qualitative study. Nagoya J Med Sci 2018;80:451-64

15 Gutema BT, Chuka A, Ayele G, et al. Predictive capacity of obesity indices for high blood pressure among southern Ethiopian adult population: a who steps survey. BMC Cardiovasc Disord 2020;20:421.

16 Hassen B, Mamo H. Prevalence and associated anthropometric and lifestyle predictors of hypertension among adults in Kombolcha town and suburbs, northeast Ethiopia: a community-based cross-sectional study. BMC Cardiovasc Disord 2019;19:241.

17 Zekewos A, Egeno T, Loha E. The magnitude of hypertension and its risk factors in southern Ethiopia: a community based study. PLoS One 2019;14:e0221726.

18 Ahmad N, Adam SI, Nawi AM. Abdominal obesity indicators: waist circumference or Waist-to-hip ratio in Malaysian adults population. Int J Prev Med 2016;8:82.

19 Neter JE, Stam BE, Kok FJ, et al. Influence of weight reduction on blood pressure: a meta-analysis of randomized controlled trials. Hypertension 2003;42:878-84.

20 He FJ, Li J, Macgregor GA. Effect of longer term modest salt reduction on blood pressure: cochrane systematic review and metaanalysis of randomised trials. BMJ 2013;346:f1325.

21 Cox BD, Whichelow MJ, Ashwell M, et al. Association of anthropometric indices with elevated blood pressure in British adults. Int J Obes Relat Metab Disord 1997;21:674-80.

22 Faramarzi E, Ostadrahimi A, Nikniaz Z, et al. Determination of the Best Anthropometric Index of Obesity for Prediction of Prehypertension and Hypertension in a Large Population - Based Study; the Azar- Cohort. Iran Red Crescent Med J 2018;20:e59911.

23 Fuchs FD, Gus M, Moreira LB, et al. Anthropometric indices and the incidence of hypertension: a comparative analysis. Obes Res 2005;13:1515-7.

24 Staub K, Floris J, Koepke N, et al. Associations between anthropometric indices, blood pressure and physical fitness performance in young Swiss men: a cross-sectional study. BMJ Open 2018;8:e018664.

25 Chobanian AV, Bakris GL, Black HR, et al. The seventh report of the joint National Committee on prevention, detection, evaluation, and treatment of high blood pressure: the JNC 7 report. JAMA 2003;289:2560-71

26 Krakoff LR, Gillespie RL, Ferdinand KC, et al. 2014 hypertension recommendations from the eighth joint National Committee pane members raise concerns for elderly black and female populations. $J$ Am Coll Cardiol 2014;64:394-402.

27 World Health Organization. A global brief on hypertension, 2013. Available: https://www.who.int/cardiovascular_diseases/publications/ global_brief_hypertension/en/ [Accessed 9 Feb 2021].

28 Yatsuya H. Risk Prediction. In: Vasan R, Sawyer D, eds. The encyclopedia of cardiovascular research and medicine. Oxford, UK: Elsevier, 2018: 4. 315-8.

29 Liu Y, Tong G, Tong W, et al. Can body mass index, waist circumference, waist-hip ratio and waist-height ratio predict the presence of multiple metabolic risk factors in Chinese subjects? BMC Public Health 2011;11:35.

30 Decoda Study Group, Nyamdorj R, Qiao Q, et al. BMI compared with central obesity indicators in relation to diabetes and hypertension in Asians. Obesity 2008;16:1622-35

31 Sakurai M, Miura K, Takamura T, et al. Gender differences in the association between anthropometric indices of obesity and blood pressure in Japanese. Hypertens Res 2006;29:75-80.

32 Siani A, Cappuccio FP, Barba G, et al. The relationship of waist circumference to blood pressure: the Olivetti heart study. Am J Hypertens 2002;15:780-6.

33 Wang Y, Howard AG, Adair LS, et al. Waist circumference change is associated with blood pressure change independent of BMI change. Obesity 2020;28:146-53.

34 Yap S, Yang Z, Wang J, et al. Waist circumference, not body mass index, is associated with blood pressure in a sample of young Chinese adults. J Hum Hypertens 2006;20:904-6.

35 Obesity in Asia Collaboration. Is central obesity a better discriminator of the risk of hypertension than body mass index in ethnically diverse populations? J Hypertens 2008;26:169-77.

36 Feng R-N, Zhao C, Wang C, et al. Bmi is strongly associated with hypertension, and waist circumference is strongly associated with type 2 diabetes and dyslipidemia, in northern Chinese adults. $J$ Epidemiol 2012;22:317-23.

37 Oda E, Kawai R. Body mass index is more strongly associated with hypertension than waist circumference in apparently healthy Japanese men and women. Acta Diabetol 2010;47:309-13.

38 Gebremariam LW, Hirakawa Y, Rayna SE, et al. Pilot peer health education for noncommunicable disease prevention in Bangladesh, Ethiopia, and Palau. J Glob Health Rep 2018;2:e2018039. 